DOI: https://doi.org/10.30749/2594-8261.v4n3p178-194

\title{
CRISE CARCERÁRIA EM TEMPOS DE PANDEMIA
}

\section{CRISIS CARCELARIA EN TIEMPOS DE PANDEMIA}

\section{Sergio Andrés López Zamora Stephanie Carolyn Perez}

Resumo: A pandemia da Covid-19 colocou em evidência a gravidade de alguns problemas já antigos e conhecidos nos sistemas jurídicos da América do Sul, como por exemplo a questão da superlotação carcerária, o que levou ao questionamento de como estes problemas se intensificaram e o quão críticas são as condições que os cercam. A proposta deste artigo é analisar a superlotação carcerária e os problemas enfrentados pela população privada de liberdade durante a situação de pandemia, especialmente no Brasil e na Colômbia.

Palavras-Chave: Covid-19. Coronavírus. Crise Carcerária. América Do Sul. Superlotação.

Resumen: La pandemia del Covid-19 destacó la gravedad de algunos problemas ya tradicionales y bien conocidos en los sistemas jurídicos suramericanos, como el problema del hacinamiento en las cárceles, lo que llevó a la pregunta de cómo estos problemas se intensificaron y cuán críticos son las condiciones que les rodean. El propósito de este artículo es analizar el hacinamiento carcelario y los problemas que enfrenta la población privada de libertad durante la situación pandémica, especialmente en Brasil y Colombia.

Palabras Clave: Covid-19. Coronavirus. Crisis Carcelaria. Suramérica. Hacinamiento.

\footnotetext{
* Advogado. Mestre em Direito Penal e Processo Penal pela Universidad Santo Tomás (Colômbia). Doutorando em Direito Público pela Universidad Santo Tomás e Doutorando em Direito Penal pela Universidad de Buenos Aires (UBA- Argentina). Professor vinculado ao grupo de pesquisa Hugro Grocio do Centro de Investigação e Inovação da Fundacion Universitaria Juan de Castellanos (Tunja, Colômbia). E-mail: salopez@jdc.edu.co

** Advogada criminal. Doutoranda em Direito Penal pela Universidad de Buenos Aires (UBA Argentina). Mestre e Bacharel em Direito pela Pontifícia Universidade Católica de São Paulo (PUCSP). Professora das disciplinas de Direito Penal, Direito Processual Penal e Execução Penal nos cursos de graduação e pós-graduação. Autora de artigos jurídicos publicados no Brasil e no exterior. E-mail: stephanie_carolyn@hotmail.com
} 


\section{INTRODUÇÃO}

O objetivo deste artigo é analisar a grave problemática que envolve a superlotação das penitenciárias, questão antiga e que se tornou ainda mais evidente em razão da propagação do vírus da Covid-19, afetando significativamente a crise carcerária enfrentada por diversos países da América do Sul, especialmente pelo Brasil e pela Colômbia.

O resultado apresentado ao leitor é produto de uma investigação dogmática e jurídica. Partindo de um método de pesquisa analítico-descritivo, foram utilizados como ferramentas as disposições normativas que regulam a matéria, com o objetivo de fornecer ao leitor uma análise objetiva e ao mesmo tempo fundamentada não apenas nos dados da realidade do sistema carcerário, mas também na normativa que regula o tema.

Neste sentido, o artigo responde à seguinte questão: Qual a situação da crise carcerária enfrentada pelo Brasil e pela Colômbia em tempos de pandemia? Como objetivos específicos da pesquisa foram estabelecidos: (i) determinar a situação carcerária atual no Brasil; e (ii) estabelecer a situação carcerária atual na Colômbia, como será visto a seguir.

\section{CRISE CARCERÁRIA NO BRASIL}

\subsection{Antecedentes}

A crise carcerária, especialmente no que se refere à superlotação, é um problema que sempre existiu. O que a pandemia fez foi apenas intensificar e dar visibilidade a este grande colapso carcerário.

A situação das penitenciárias no Brasil - e em muitos países ao redor do mundo, especialmente nos países da América do Sul - já era insustentável há muito tempo. São precárias condições dos centro penitenciários associadas à ausência de infraestrutura física e institucional, desumanização das pessoas que estão sob a custódia do Estado, superlotação carcerária, entre outras características que lamentavelmente expressam a ineficácia do Estado para enfrentar a situação e fornecer um tratamento digno às pessoas que fazem parte do sistema penitenciário, o que faz dos centros penitenciários espaços de tortura não somente para aqueles 
que estão presos, mas também para os seus familiares e todos os trabalhadores e colaboradores do sistema prisional.

Pregunta-se: por que as pessoas estão presas? Por que há pessoas presas? O que se espera como resposta é: porque são culpados. Ou seja: estão presas porque responderam a um processo, foram condenadas, foi proferida sentença penal condenatória e houve o trânsito em julgado da decisão condenatória. Claro que no mundo ideal assim deveria ser, mas não é. A verdade é que a grande maioria dos presos não são culpados. E não o são não porque foram presos injustamente ou porque sejam todos inocentes, mas sim porque para que sejam culpados é necessário que tenham sido condenados por uma sentença penal condenatória que tenha transitado em julgado. Enquanto não exista uma sentença condenatória com trânsito em julgado a pessoa é inocente perante a lei e principalmente perante o Estado Democrático de Direito.

Os que estão presos em sua grande maioria são pessoas que não têm uma sentença condenatória transitada em julgado. Na grande maioria dos casos, sequer existe uma condenação. Estão presos simplesmente porque molestam e incomodam a sociedade. Sejam ou não culpados, tenham ou não uma condenação, devemos desde já dizer algo: um preso é um ser humano, independentemente de qual tenha sido o crime praticado. O preso é e sempre será um ser humano.

Não podemos nos esquecer de que há pessoas que estão presas em lugares que sequer foram criados para serem prisões, como por exemplo as delegacias de polícia, que além de não possuir infraestrutura para custodiar presos não possuem funcionários com formações específicas e preparo para atuar dentro do sistema penitenciário. As delegacias foram criadas para que, se uma pessoa vier a ser presa, passe a noite na delegacia e no dia seguinte seja apresentada perante a autoridade judicial, e não para ficar detida de forma permanente.

Feitas essas considerações iniciais, passemos a analisar a situação dos estabelecimentos prisionais no Brasil que enfrentam há muito tempo, uma das situações mais preocupantes na América do Sul. As penitenciárias brasileiras são lugares onde não há justiça e tampouco humanidade.

Para que se tenha uma ideia da situação atual no Brasil, é preciso apresentar alguns dados obtidos no Levantamento Nacional de Informações Penitenciárias Dezembro de 2019, disponível no site do Departamento Penitenciário Nacional: o Brasil tinha uma população de 748.009 mil presos contabilizada até 
dezembro de 2019, dentre os quais 362.547 estão presos em regime fechado, 133.408 mil estão presos no regime semiaberto, 25.137 mil estão no regime aberto e 222.558 mil são presos provisórios, ou seja, não foram condenados por uma sentença proferida em um processo penal (a grande maioria sequer foi processada ainda), conforme gráfico abaixo:

Gráfico 1 - População Carcerária no Brasil: Levantamento Nacional de Informações Penitenciárias: dezembro de 2019

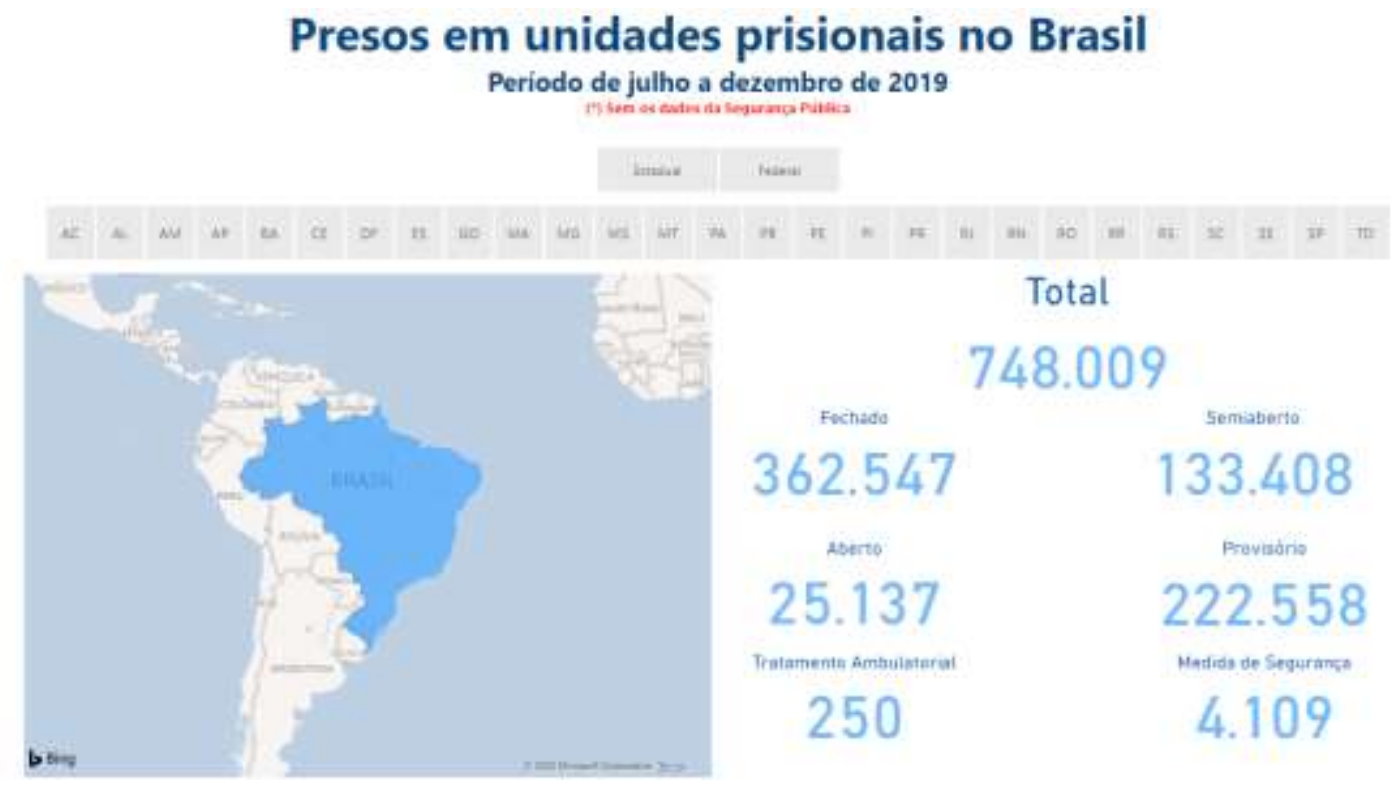

Fonte: Departamento Penitenciário Nacional ([2020]).

Estar preso no Brasil significa perder os direitos humanos para uma vida digna. No Brasil não são respeitadas as mínimas garantias de dignidade humana: não há chuveiros ou torneiras para que todos os presos possam fazer sua higiene pessoal, não há agua potável, a comida não tem qualidade. Há uma preocupante superlotação. Os presos não podem ser atendidos por um médico quando ficam doentes. Os estabelecimentos prisionais não têm sequer os medicamentos básicos para tratar dos presos que apresentem sintomas como febre ou dor de cabeça. Os pavilhões não têm estrutura para separar os presos com enfermidades graves como pneumonia, doença de Chagas e câncer, daqueles que estão saudáveis. Os pavilhões não passam por limpeza ou dedetização. Não há condições mínimas de higiene nestes espaços. No Brasil a privação de liberdade está acompanhada de uma grave e violadora privação de direitos humanos. 
Os estabelecimentos penitenciários além de não cumprirem com seu objetivo resocializador não garantem a segurança e saúde dos presos e os desumanizam, tornando-os vulneráveis às situações degradantes que existem nestes espaços.

Por mais óbvio que possa parecer, algo precisa ser dito: os presos não são somente presos. São pessoas. São seres humanos. Têm e devem ter garantidos o direito à vida, à dignidade, à saúde, à intimidade, etc. $\mathrm{O}$ fato de estarem privados de sua liberdade não lhes retira o direito de serem tratados como seres humanos. A pessoa que é condenada pela prática de um crime não deixa de ser pessoa. Somente se limitam seus direitos, sempre de maneira transitória, e não definitiva. Tanto assim, que uma das finalidades da pena é justamente a ressocialização do condenado.

Foi nestes estabelecimentos que chegou a pandemia causada pela Covid19. Nestes lugares onde há superlotação e onde não há higiene e limpeza é que se instalou um vírus com enorme poder letal. Por isso, o contágio pela Covid-19 pode ocorrer de forma extremamente superior entre a população carcerária do que entre a população que não está presa. Se trata de uma questão grave porque a população carcerária é vulnerável em razão das condições precárias a que estão submetidos os presos.

Os presos, embora estejam presos, também podem e vão se contaminar com a Covid-19. E quando isso acontecer, irão utilizar os mesmos recursos de saúde que as pessoas que não estão presas, o que certamente poderá causar um colapso no sistema de saúde.

Por isso, organismos internacionais como a Organização Mundial da Saúde (OMS), a Organização das Nações Unidas (ONU), o Comitê Internacional da Cruz Vermelha (CICV) e a Comissão Interamericana de Direitos Humanos (CIDH) emitiram recomendações para evitar o ingresso e propagação da Covid-19 nas penitenciárias, a fim de evitar uma catástrofe sanitária.

De acordo com o manual publicado em 15 de março de 2020 pela $\mathrm{OMS}^{1}$, o esforço global para tratar do controle da propagação da Covid-19 pode falhar se não

\footnotetext{
${ }_{1}^{1}$ A OMS publicou em 15.03.2020 um guia para tratar do tema da Covid-19 nas prisões, solicitando aos governos que criem um sistema de coordenação entre os setores de Saúde e Justiça, junto com os funcionários penitenciários, de forma a combater o vírus e sua propagação entre a população carcerária. O guia, intitulado "Preparação, prevenção e controle de Covid-19 em prisões e outros
} 
houver a atenção necessária às medidas de controle de infecções dentro das penitenciárias. (WORLD HEALTH ORGANIZATION, 2020).

Seguindo estas recomendações, os países começaram então a adotar medidas de excarceração, como ocorreu na França, Estados Unidos, Argentina, Itália e claro, no Brasil.

Essas medidas de excarceração não foram adotadas por clemência ou por piedade aos presos, mas sim como uma forma de reduzir os fatores de risco de contágio e contaminação entre a população carcerária e assim, proteger a saúde de cada um de nós, ou seja: proteger a saúde dos que estão presos e também daquelas pessoas que não estão.

A seguir abordaremos as medidas adotadas pelo sistema judiciário brasileiro para combater a propagação da Covid-19 nas penitenciárias brasileiras.

\subsection{Medidas adotadas pelo Brasil para conter a propagação da Covid-19 nos estabelecimentos prisionais}

Em meio ao aumento de casos no país e demonstrando forte preocupação com a população carcerária, o Conselho Nacional de Justiça (CNJ) publicou a Recomendação ํㅜ 62, de 17.03.2020 (CONSELHO NACIONAL DE JUSTIÇA, 2020), direcionada aos tribunais e magistrados, para adoção de medidas preventivas contra a propagação da Covid-19 no sistema de justiça penal e socioeducativo. Referido documento teve como objetivo indicar às autoridades judiciais algumas recomendações práticas para reduzir o impacto da pandemia da Covid-19 nos locais de detenção a fim de proteger a saúde e o bem-estar de todos aqueles que vivem, trabalham e visitam as penitenciárias.

Como o próprio nome já diz, se trata de uma recomendação. Ainda assim, o que se viu após a sua publicação foi tribunais e magistrados seguindo as recomendações indicadas pelo $\mathrm{CNJ}$, permitindo assim a liberdade excepcional à determinadas pessoas, uma vez cumpridos os requisitos indicados na própria recomendação.

Em uma abordagem objetiva, a Recomendação nํ 62 estabelece que com relação às pessoas custodiadas, devem ser reanalisadas as prisões provisórias,

locais de detenção" fornece informações para profissionais de saúde que trabalham em prisões e autoridades penitenciárias. (WORLD HEALTH ORGANIZATION, 2020). 
especialmente com relação às pessoas que pertençam aos grupos mais vulneráveis, como mães, pessoas com deficiência, idosos ou pessoas que estejam presas em estabelecimentos com superlotação e onde não haja atendimento médico. Também foi recomendada a reanálise da situação de pessoas presas por mais de 90 dias ou que estejam presas por crimes que não sejam graves, ou seja, aqueles crimes cometidos sem violência ou sem ameaça contra a vítima. Com relação aos presos que já estejam cumprindo pena, a Recomendação nº 62 estabelece que os juízes avaliem a possibilidade de conceder de maneira antecipada a liberdade condicional ou a saída antecipada para casos previstos expressamente em lei.

Outra recomendação é de que o julgador conceda prisão domiciliar aos presos que estejam cumprindo pena em regime aberto ou semiaberto ou quando o preso apresentar sintomas da Covid-19. É possível verificar, portanto, que a Recomendação no 62 busca reduzir o fluxo de pessoas presas neste momento de pandemia.

Também é recomendada: (i) a suspensão da realização de audiências de custódia; (ii) realização de audiências regulares por meio de videoconferência; e (iii) adoção de medidas preventivas de saúde nos espaços públicos, como por exemplo, disponibilizar água, sabão líquido, álcool em gel e máscaras de proteção para reduzir a contaminação.

Assim dispõe a Recomendação $n^{\circ}$ 62:

Art. 4ํ Recomendar aos magistrados com competência para a fase de conhecimento criminal que, com vistas à redução dos riscos epidemiológicos e em observância ao contexto local de disseminação do vírus, considerem as seguintes medidas:

I - a reavaliação das prisões provisórias, nos termos do art. 316, do Código de Processo Penal, priorizando-se: a) mulheres gestantes, lactantes, mães ou pessoas responsáveis por criança de até doze anos ou por pessoa com deficiência, assim como idosos, indígenas, pessoas com deficiência ou que se enquadrem no grupo de risco; b) pessoas presas em estabelecimentos penais que estejam com ocupação superior à capacidade, que não disponham de equipe de saúde lotada no estabelecimento, que estejam sob ordem de interdição, com medidas cautelares determinadas por órgão do sistema de jurisdição internacional, ou que disponham de instalações que favoreçam a propagação do novo coronavírus; c) prisões preventivas que tenham excedido o prazo de 90 (noventa) dias ou que estejam relacionadas a crimes praticados sem violência ou grave ameaça à pessoa;

(...)

Art. 5을 Recomendar aos magistrados com competência sobre a execução penal que, com vistas à redução dos riscos epidemiológicos e em observância ao contexto local de disseminação do vírus, considerem as seguintes medidas: I - concessão de saída antecipada dos regimes fechado e semiaberto, nos termos das diretrizes fixadas pela Súmula Vinculante no 56 do Supremo Tribunal Federal, sobretudo em relação às: a) mulheres 
gestantes, lactantes, mães ou pessoas responsáveis por criança de até 12 anos ou por pessoa com deficiência, assim como idosos, indígenas, pessoas com deficiência e demais pessoas presas que se enquadrem no grupo de risco; b) pessoas presas em estabelecimentos penais com ocupação superior à capacidade, que não disponham de equipe de saúde lotada no estabelecimento, sob ordem de interdição, com medidas cautelares determinadas por órgão de sistema de jurisdição internacional, ou que disponham de instalações que favoreçam a propagação do novo coronavírus; II - alinhamento do cronograma de saídas temporárias ao plano de contingência previsto no artigo 9ำ da presente Recomendação, avaliando eventual necessidade de prorrogação do prazo de retorno ou adiamento do benefício, assegurado, no último caso, o reagendamento da saída temporária após o término do período de restrição sanitária; III concessão de prisão domiciliar em relação a todos as pessoas presas em cumprimento de pena em regime aberto e semiaberto, mediante condições a serem definidas pelo Juiz da execução; IV - colocação em prisão domiciliar de pessoa presa com diagnóstico suspeito ou confirmado de Covid-19, mediante relatório da equipe de saúde, na ausência de espaço de isolamento adequado no estabelecimento penal; $\mathrm{V}$ - suspensão temporária do dever de apresentação regular em juízo das pessoas em cumprimento de pena no regime aberto, prisão domiciliar, penas restritivas de direitos, suspensão da execução da pena (sursis) e livramento condicional, pelo prazo de noventa dias; (...)

Art. $7^{\circ}$ Recomendar aos Tribunais e magistrados com competência penal que priorizem a redesignação de audiências em processos em que o réu esteja solto e a sua realização por videoconferência nas hipóteses em que a pessoa esteja privada de liberdade, com vistas à redução dos riscos epidemiológicos e em observância ao contexto local de disseminação do vírus. $\S 10 \mathrm{Na}$ hipótese de manutenção da realização de audiências, recomenda-se a adoção das seguintes medidas: I - restrição temporária da presença de visitantes do público em geral no recinto durante a solenidade; II - realização da audiência em espaços ampliados ou abertos, tais como salas destinadas aos plenários do júri e auditórios, permitindo maior distância respiratória entre as pessoas presentes; III - substituição temporária de magistrados e agentes públicos que pertençam ao grupo de risco; IV - adoção de medidas de higiene e de prevenção, tais como disponibilização de água corrente e sabão líquido, utilização de máscaras, álcool gel e outros produtos que possam reduzir o risco de contaminação e limpeza minuciosa das superfícies; $V$ - garantia de salubridade e medidas de isolamento, quando necessário, na carceragem adjacente à sala de audiência; $\mathrm{VI}$ - uso excepcional de algemas, que devem ser higienizadas com material antiviral; VII - redução do tempo de permanência nas carceragens dos Fóruns. (CONSELHO NACIONAL DE JUSTIÇA, 2020).

Com base na referida Recomendação e diante da situação que se instalava no Brasil, em 18.03.2020, o Supremo Tribunal Federal recomendou aos juízes a reavaliação, com urgência, da situação das pessoas que se encontravam presas e que pertencessem ao grupo de risco, como idosos, pessoas com doenças crônicas e mulheres grávidas, a fim de que tais pessoas fossem retiradas do ambiente carcerário em razão da propagação do coronavírus no Brasil. Essa recomendação foi proferida no julgamento da Tutela Provisória Incidental na Arguição de Descumprimento de Preceito Fundamental no 347, nos seguintes termos: 
Ante a situação precária e desumana dos presídios e penitenciárias, no que levou o Colegiado Maior, na medida cautelar na arguição de descumprimento de preceito fundamental $n^{\circ} 347 / \mathrm{DF}$, a concluir pelo estado de coisas inconstitucional, considerada a integridade física e moral dos custodiados, assento a conveniência e, até mesmo, a necessidade de o Plenário pronunciar-se.

De imediato, conclamo os Juízos da Execução a analisarem, ante a pandemia que chega ao País - infecção pelo vírus COVID19, conhecido, em geral, como coronavírus -, as providências sugeridas, contando com o necessário apoio dos Tribunais de Justiça e Regionais Federais. A par da cautela no tocante à população carcerária, tendo em conta a orientação do Ministério da Saúde de segregação por catorze dias, eis as medidas processuais a serem, com urgência maior, examinadas: a) liberdade condicional a encarcerados com idade igual ou superior a sessenta anos, nos termos do artigo $1^{\circ}$ da Lei ํㅜ 10.741 , de $1^{\circ}$ de outubro de 2003 ; b) regime domiciliar aos soropositivos para HIV, diabéticos, portadores de tuberculose, câncer, doenças respiratórias, cardíacas, imunodepressoras ou outras suscetíveis de agravamento a partir do contágio pelo COVID-19; c) regime domiciliar às gestantes e lactantes, na forma da Lei oㅜ 13.257, de 8 de março de 2016 - Estatuto da Primeira Infância; d) regime domiciliar a presos por crimes cometidos sem violência ou grave ameaça; e) substituição da prisão provisória por medida alternativa em razão de delitos praticados sem violência ou grave ameaça; f) medidas alternativas a presos em flagrante ante o cometimento de crimes sem violência ou grave ameaça; g) progressão de pena a quem, atendido o critério temporal, aguarda exame criminológico; e h) progressão antecipada de pena a submetidos ao regime semiaberto. (BRASIL, 2020).

Diante da propagação da pandemia, os países começaram a adotar medidas de excarceração dos presos porque a Covid-19 deu visibilidade às debilidades e fraquezas do sistema penitenciário no Brasil. Foram medidas de emergência adotadas como resposta à propagação da Covid-19 para reduzir a população privada de liberdade a fim de prevenir as consequências devastadoras que o coronavírus poderia ter dentro do sistema penitenciário. Isso porque em países onde o coronavírus chegou antes do Brasil, foram confirmados muitos casos e mortes entre presos e agentes penitenciários causadas pela Covid-19. Por isso, muitos países adotaram medidas para reduzir a população carcerária como estratégia para prevenir a propagação da doença.

Não apenas o Brasil, mas todos os países ao redor do mundo estão enfrentando neste momento a necessidade de adotar políticas públicas, medidas e ações com o objetivo de evitar o contágio pelo coronavírus e salvar vidas, especialmente com relação à população carcerária que em razão da vulnerabilidade a que está submetida, necessita de atenção especial.

Estas medidas são extremamente importantes porque os presos, sejam ou não culpados, tenham ou não condenação transitada em julgado, precisam fazer o isolamento. Como vão ficar isolados em pavilhões pensados para 20 pessoas e 
onde há 150 pessoas ou mais? É impossível o distanciamento e isolamento social nessas condições.

É importante reforçar que dentro do sistema penitenciário são vulneráveis não somente os presos que estejam sob a custodia do Estado, mas também as pessoas que trabalham dentro das penitenciárias. Essas pessoas que passam o dia dentro das delegacias e das penitenciárias ao final do dia voltam para suas casas, onde estão seus familiares. Temos também os advogados que vão conversar com seus clientes. Se essas pessoas se contaminam, há grande probabilidade de que transmitam o vírus aos seus familiares também. É por essa razão que se faz importante cuidar de todos os que estão inseridos no sistema carcerário: os presos e as pessoas que lá trabalham todos os dias.

As medidas recomendadas pelo Conselho Nacional de Justiça por meio da Recomendação no 62 não constituem uma anistia. Não apagam o crime. Também não podem ser consideradas como uma forma de comutação da pena. São apenas e tão somente medidas de emergência recomendadas para um período transitório. Nada mais. Uma vez tudo volte ao normal, os presos vão voltar para a penitenciária e voltará também toda a discussão sobre o problema da superlotação e tantos outros, tal como era antes da pandemia.

As medidas recomendadas pelo Conselho Nacional de Justiça estão baseadas no dever do Estado de proteger todos os cidadãos brasileiros, estejam ou não presos. Trata-se, ainda, da obediência aos parâmetros internacionais de proteção dos direitos humanos fundamentais, tais como a dignidade humana, 0 direito à vida, à integridade física e a proibição de penas desumanas ou cruéis.

É necessário que exista um controle eficaz da propagação do coronavírus dentro do sistema penitenciário, por meio de uma ação conjunta entre os setores de saúde, sanitário e também do Poder Judiciário. O coronavírus tem um poder letal devastador, que trouxe consequências catastróficas sem precedentes, imprevisíveis e incalculáveis.

O confinamento sob uma superlotação torna as prisões locais especialmente vulneráveis para a transmissão do vírus, colocando em risco a saúde das pessoas. Nesse contexto, surge para o Estado, para as instituições políticas e para o sistema judiciário o dever de garantir os direitos subjetivos dos presos.

A seguir, veremos o panorama da questão na Colômbia. 


\section{CRISE CARCERÁRIA NA COLÔMBIA}

O crescimento vertiginoso do surto do vírus na Colômbia levou o governo a declarar estado de emergência, com o propósito específico de enfrentar o vírus da Covid-19. A situação jurídica era legal e, de forma significativa os valores constitucionais foram respeitados ${ }^{2}$.

Por isso, no âmbito judicial, foi declarada a suspensão da tramitação dos processos penais que estavam em andamento penal, inclusive dos atos processuais. Neste cenário, a expansão virtual chegou logo e as audiências dos processos penais foram retomadas e passaram a ser adaptadas com agilidade com o auxílio de aplicativos como Zoom, Google Meet, Lifesize e outros.

Com relação às prisões em vigor, estas não foram beneficiadas com as medidas adotadas, já que o presidente colombiano Iván Duque promulgou o Decreto nํ 546 de 2020 (COLÔMBIA, 2020b), que embora preveja medidas temporárias para restrição da liberdade em tempos de pandemia, dando prioridade, por exemplo, à decretação de prisões domiciliares, na prática, o decreto cria um rol de crimes excluídos desse benefício, que somadas com as restrições já existentes no Código Penal Colombiano (COLÔMBIA, 2020c), fez com que as disposições do decreto não passassem de letra morta no papel, ou ainda, apenas versos de poesia.

Embora a gestão estatal do vírus na Colômbia tenha deixado muito a desejar, a verdade é que o Decreto no 546 de 2020 (COLÔMBIA, 2020b) reconhece os problemas e riscos gerados pela superlotação carcerária, tomando como base 0 Comunicado de Imprensa no 66/20, de 31 de março de 2020, por meio do qual a Corte Interamericana dos Direitos Humanos expressa sua preocupação com as condições das pessoas privadas de liberdade na América do Sul, principalmente devido às precárias condições de higiene, saneamento e níveis extremos de superlotação que em alguns países ultrapassam 300\% (especificamente no caso da Bolívia) (ORGANIZACIÓN DE LOS ESTADOS AMERICANOS, 2020).

No caso da Colômbia, no ano de 2020 os índices de superlotação chegavam a $54,9 \%$ com um total de 124.188 pessoas presas. De acordo com a capacidade das 132 prisões do país, existem apenas 80.156 vagas. (ROJAS CASTAÑEDA, 2020). Estes números vêm aumentando consideravelmente nos últimos anos, se levarmos

2 Na Colômbia, a atual Constituição Política foi promulgada em 1991. (COLÔMBIA, 2020a). 
em conta que em 1990 eram apenas 32.000 vagas (LÓPEZ ZAMORA, 2013), em comparação com os números que aumentam constantemente, como mostra o quadro a seguir:

Quadro 1 - Relatório sobre os direitos humanos do sistema penitenciário da Colômbia (2017-2018)

\begin{tabular}{|c|c|c|c|}
\hline Año & $\begin{array}{c}\text { Capacidad de los esta- } \\
\text { blecimientos carcela- } \\
\text { rios }\end{array}$ & Cantidad de internos & $\begin{array}{c}\text { Índice de hacinamien- } \\
\text { to }\end{array}$ \\
\hline 2011 & 75.620 & 100.451 & $32.8 \%$ \\
\hline 2012 & 75.726 & 113.884 & 50.4 \\
\hline 2013 & 76.066 & 120.032 & $57,8 \%$ \\
\hline 2014 & 77.874 & 113.623 & $45,9 \%$ \\
\hline 2015 & 77.953 & 120.444 & $54,5 \%$ \\
\hline 2016 & 77.953 & 118.532 & $51,2 \%$ \\
\hline 2017 & 78.418 & 118.925 & $51.7 \%$ \\
\hline
\end{tabular}

Fonte: (ARISTIZABAL et al., 2019).

Achamos que em tempos de pandemia a crise carcerária deveria ter se concentrado apenas na questão da superlotação, levando em conta que foi afirmado pelo Alto Comissariado das Nações Unidas para os Direitos Humanos, que desde 25 de março de 2020 manifestou sua preocupação porque o vírus já estava se espalhando no meio carcerário, colocando em risco real e evidente pessoas privadas de liberdade, as quais estão em situação de extrema vulnerabilidade. (BACHELET, 2020). No entanto, infelizmente a crise carcerária enfrentada em tempos de pandemia não está restrita apenas à superlotação. Na Colômbia a crise foi além: houve aumento do ajuizamento de ações penais referentes às pessoas que não cumpriram as medidas de confinamento exigidas pelo governo colombiano como estratégia para enfrentar o surto do vírus, contribuindo com o alto índice de criminalidade no país, já que a disseminação do vírus não impediu a atividade criminosa.

Até aqui, é possível concluir que a Colômbia não acatou as sugestões internacionais que identificaram a superlotação carcerária como um problema que deveria ser tratado e combatido de forma urgente, visto que a implementação das medidas de excarceração ficaram aquém das boas intenções que estão previstas no Decreto nํ5 546 de 2020 (COLÔMBIA, 2020b). Essa é a atual situação enfrentada em 
tempos de pandemia: os governos não levam em consideração as condições subumanas das pessoas privadas de liberdade na gestão de sua política criminal.

Finalmente, foi feita uma análise da situação das prisões em alguns países da América do Sul, por meio da qual foram identificados os seguintes números atualizados (países como Argentina ou Uruguai não relatam taxas de superlotação em seus sistemas penitenciários):

Quadro 2 - Análise da situação das prisões em alguns países da América do Sul

\begin{tabular}{|c|c|c|}
\hline PAÍS & $\begin{array}{c}\text { POPULAÇÃO EM } \\
\text { CENTROS DE PRISÃO }\end{array}$ & $\begin{array}{c}\text { SUPERLOTAÇÃO EM } \\
\text { PRISÕES }\end{array}$ \\
\hline ARGENTINA & $\begin{array}{l}63.094 \\
\text { (LA POBLACIÓN..., 2019) }\end{array}$ & $0 \%(2019)$ \\
\hline BRASIL & $\begin{array}{l}758.676 \\
\text { (EL NÚMERO.., 2020) }\end{array}$ & $50,0 \%(2020)$ \\
\hline BOLÍVIA & $\begin{array}{l}15.600 \\
\text { (EL HACINAMIENTO..., } \\
2017 \text { ). }\end{array}$ & $290,0 \%(2017)$ \\
\hline CHILE & $\begin{array}{l}42.000 \\
\text { (ABATE, 2020). }\end{array}$ & $4,0 \%(2020)$ \\
\hline COLÔMBIA & $\begin{array}{l}124.188 \\
\text { (ROJAS CASTAÑEDA, } \\
\text { 2020). }\end{array}$ & $54,9 \%(2020)$ \\
\hline EQUADOR & $\begin{array}{l}38.797 \\
\text { (CÁRCELES, 2020). }\end{array}$ & $31,7 \%(2020)$ \\
\hline PARAGUAI & $\begin{array}{l}14.630 \\
\text { (COORDINADORA } \\
\text { DERECHOS HUMANOS } \\
\text { PARAGUAY, 2019). }\end{array}$ & $50,0 \%(2019)$ \\
\hline PERU & $\begin{array}{l}95.765 \\
\text { (EL HACINAMIENTO..., } \\
2020) .\end{array}$ & $131,0 \%(2020)$ \\
\hline URUGUAI & $\begin{array}{l}11.643 \\
\text { (INR AFIRMA..., 2019). }\end{array}$ & $0 \%(2019)$ \\
\hline VENEZUELA & $\begin{array}{l}80.000 \\
\text { (OVP: HACINAMIENTO..., } \\
\text { 2020). }\end{array}$ & $167,66 \%(2020)$ \\
\hline
\end{tabular}

Fonte: Os autores, com base nos dados retirados dos trabalhos citados no quadro.

De acordo com o exposto, pensamos que dentre os mais variados e significativos problemas que envolvem as prisões, a questão da superlotação é, sem dúvidas, o aspecto que deveria ter atraído a atenção dos governos durante a pandemia, não só por se tratar de uma questão grave e urgente, mas principalmente porque representa um problema grave que persiste já há muitas décadas na maioria dos países sul-americanos. Assim, concluímos que a crise carcerária em tempos de 
pandemia está fortemente relacionada com a superlotação enfrentada pela maioria dos países da região.

\section{CONCLUSÕES}

Este estudo mostra que o problema que merece mais atenção e que é recorrente nos países sul-americanos é a superlotação das prisões. As consequências que a América do Sul enfrenta em razão da situação causada pela Covid-19 colocam em evidência que o Estado é ineficaz para cumprir com sua função de gerir os problemas sociais, em especial aqueles relacionados com a superlotação carcerária, fazendo das prisões lugares de desumanização de direitos, tortura e condições indignas de vida.

Com relação ao Brasil, a crise carcerária não se limita apenas à questão da superlotação, mas também a forma como o Estado trata da questão das pessoas privadas de liberdade, desrespeitando as garantias mínimas de dignidade humana e violando os direitos humanos dos presos.

Com relação à Colômbia, há um problema central que rodeia a crise: a superlotação carcerária, tal como ocorre no Brasil e em outros países da América do Sul.

Apesar de que, em termos gerais, a Colômbia tenha enfrentado a Covid-19 de maneira satisfatória, as medidas tratadas em matéria penitenciária não foram eficazes e ficaram aquém das sugestões internacionais, gerando um risco iminente de propagação do vírus entre a população carcerária, já que a superlotação não foi combatida, sendo a crise carcerária permanente em tempos de pandemia.

Assim, a academia faz um apelo urgente aos organismos nacionais e internacionais para o enfrentamento dessa situação tão complicada, que sequer foi abordada com a seriedade que merece em tempos de pandemia, principalmente quando se constitui em gatilho de graves violações os direitos humanos das pessoas detidas que "vivem" de forma desumana nesses locais.

\section{REFERÊNCIAS}

ABATE, Jennifer. HACINAMIENTO, motines e indultos: la realidad de las cárceles en el contexto de la pandemia. Palabra Pública, Santiago, 5 mayo 2020. Disponível 
em: https://palabrapublica.uchile.cl/2020/05/05/la-realidad-carceles-en-pandemia/. Acesso em: 5 dez. 2020.

ARISTIZABAL, Francisco et al. Informe de Derechos Humanos del Sistema Penitenciario en Colombia (2017-2018): Grupo de Prisiones, Universidad de los Andes: Boletín del Grupo de Prisiones. Bogotá: Universidad de los Andes, 2019. Disponível em:

https://grupodeprisiones.uniandes.edu.co/images/2019/GrupoPrisiones.InformeDDH H2018.pdf. Acesso em: 5 dez. 2020.

BACHELET, Michelle. Hay que tomar medidas urgentes para evitar que el Covid19 'cause estragos en las prisiones'. Ginebra: Alta Comisión de las Naciones Unidas para los Derechos Humanos, 2020. Disponível em:

https://www.ohchr.org/SP/NewsEvents/Pages/DisplayNews.aspx?NewsID=25745\&L angID=S. Acesso em: 5 dez. 2020.

BRASIL. Supremo Tribunal Federal. Tutela provisória incidental na arguição de descumprimento de preceito fundamental no 347. Requerente: Instituto de Defesa do Direito de Defesa. Requerido: União. Relator: Min. Marco Aurélio. Brasília, DF: STF, 2020. Disponível em:

http://www.stf.jus.br/arquivo/cms/noticiaNoticiaStf/anexo/ADPF347decisao.Covid19.p df. Acesso em: 7 dez. 2020.

CÁRCELES: el dolor de cabeza del Gobierno. Criterios Digital, 5 mayo 2020. Disponível em: https://criteriosdigital.com/noticias/ecuador-chequea/carceles-enecuador-el-hacinamiento-no-se-redujo-un-10-como-afirmo-

romo/\#: :text=Es\%20correcto\%20que\%20actualmente\%20la,Moreno\%20asumi\%C3 \%B3\%20el\%20mando\%20y. Acesso em: 7 dez. 2020.

COLÔMBIA. Ley 599 de 2000, Julio 24. Código Penal. Bogotá: Avance Jurídico, 2020c. Disponível em:

http://www.secretariasenado.gov.co/senado/basedoc/ley_0599_2000.html. Acesso em: 7 dez. 2020.

COLÔMBIA. [Constituição (1991)]. Constitución Política de la República de

Colombia: Esta versión corresponde a la segunda edición corregida de la Constitución Política de Colombia, publicada en la Gaceta Constitucional No. 116 de 20 de julio de 1991. Bogotá: Avance Jurídico, 2020a. Disponível em:

http://www.secretariasenado.gov.co/senado/basedoc/constitucion_politica_1991.html . Acesso em: 8 dez. 2020.

COLÔMBIA. Decreto legislativo no 546 de 14 de abril de 2020. Por medio del cual se adoptan medidas para sustituir la pena de prisión y la medida de aseguramiento de detención preventiva en establecimientos penitenciarios y carcelarios por la prisión domiciliaria... Bogotá: Ministerio de Justicia y del Derecho, 2020b. Disponível em:

https://dapre.presidencia.gov.co/normativa/normativa/DECRETO\%20546\%20DEL\%2 014\%20DE\%20ABRIL\%20DE\%202020.pdf. Acesso em: 5 dez. 2020. 
COORDINADORA DERECHOS HUMANOS PARAGUAY. EI hacinamiento de las cárceles también expresa la crisis de la justicia en Paraguay. [S. I.: s. n.], 2019. Disponível em: http://codehupy.org.py/el-hacinamiento-de-las-carceles-tambienexpresa-la-crisis-de-la-justicia-enparaguay/\#: :text=en\%20Paraguay\%20\%E2\%80\%93\%20Codehupy,El\%20hacinamiento\%20de\%20las\%20c\%C3\%A1rceles\%20tambi\%C3\%A9n\%20ex presa,de\%20la\%20Justicia\%20en\%20Paraguay\&text=En\%20la\%20\%C3\%BAltima\% 20d\%C3\%A9cada\%20la,9\%20vivan\%20en\%20hacinamiento\%20cr\%C3\%ADtico. Acesso em: 7 dez. 2020.

CONSELHO NACIONAL DE JUSTIÇA (Brasil). Recomendação no 62, de 17 de março de 2020. Recomenda aos Tribunais e magistrados a adoção de medidas preventivas à propagação da infecção pelo novo coronavírus - Covid-19 no âmbito dos sistemas de justiça penal e socioeducativo. Brasília, DF: CNJ, 2020. Disponível em: https://www.cnj.jus.br/wp-content/uploads/2020/03/62-

Recomenda\%C3\%A7\%C3\%A3o.pdf. Acesso em: 8 dez. 2020.

DEPARTAMENTO PENINTENCIÁRIO NACIONAL (Brasil). Presos em unidades prisionais no Brasil: período de julho a dezembro de 2019. Brasília, DF: DEPEN, [2020]. Disponível em:

https://app.powerbi.com/view?r=eyJrljoiZWI2MmJmMzYtODA2MC00YmZiLWI4M2It NDU2ZmlyZjFjZGQ0liwidCI6ImViMDkwNDIwLTQ0NGMtNDNmNy05MWYyLTRiOG RhNmJmZThIMSJ9. Acesso em: 7 dez. 2020.

EL HACINAMIENTO en cárceles es del $290 \%$ por detenciones preventivas.

Urgente.bo, La Paz, 12 ene. 2017. Disponível em: https://urgente.bo/noticia/elhacinamiento-en-c\%C3\%A1 rceles-es-del-290-por-detenciones-preventivas. Acesso em: 4 dez. 2020.

EL HACINAMIENTO en las cárceles peruanas en el marco de la pandemia COVID19. Pólemos: Portal Jurídico Interdisciplinario, San Miguel, 15 abr. 2020. Disponível em: https://polemos.pe/el-hacinamiento-en-las-carceles-peruanas-en-el-marco-de-lapandemia-del-covid-19/. Acesso em: 9 dez. 2020.

EL NÚMERO de presos saltó 60\% en 10 años en Brasil pero el hacinamiento continua. Agencia EFE, Rio de Janeiro, 14 feb. 2020. Disponível em:

https://www.efe.com/efe/america/sociedad/el-numero-de-presos-salto-60-en-10anos-brasil-pero-hacinamiento-continua/20000013-4174098. Acesso em: 8 dez. 2020.

OVP: HACINAMIENTO de las cárceles en Venezuela es de 167,66\%. EN: EI Nacional, 21 jul. 2020. Disponível em: https://www.elnacional.com/venezuela/ovphacinamiento-de-las-carceles-en-venezuela-es-de-16766/\#: :text=Home,OVP\%3A\%20Hacinamiento\%20de\%20las\%20c\%C3\%A1rceles,Venezuela\%20es\% 20de\%20167\%2C66\%25\&text=De\%20104\%20privados\%20de\%20libertad,por\%20e nfermedades\%20relacionadas\%20con\%20desnutrici\%C3\%B3n.\&text=\%E2\%80\%9C En\%20el\%20pa\%C3\%ADs\%2C\%20las\%20c\%C3\%A1rceles,hacinamiento\%20de\%2 0167\%2C66\%25. Acesso em: 8 dez. 2020. 
INR AFIRMA que 'superó' el 'hacinamiento estructural' en el sistema carcelario. El País, Madri, 6 dec. 2019. Disponível em:

https://www.elpais.com.uy/informacion/policiales/inr-supero-momento-hacinamientocarceles-uruguayas.html. Acesso em: 9 dez. 2020.

LÓPEZ ZAMORA, Sergio Andrés. Análisis de la crisis carcelaria en Colombia. In: BOLÍVAR MOJICA, Eyder; HIGUERA JIMÉNEZ, Diego Mauricio (comp.). Estudios en Derecho Penal: trabajos de investigación formativa producto del trabajo conjunto entre programas de pregrado y posgrado. Colombia: Sello Editorial de la Universidad Santo Tomás Seccional Tunja, 2013. p. 85-103.

ORGANIZACIÓN DE LOS ESTADOS AMERICANOS. La CIDH urge a los Estados a garantizar la salud y la integridad de las personas privadas de libertad y sus familias frente a la pandemia del COVID-19. Washington, DC: OEA, 2020. Prensa, Comunicados, 2020, 066. Disponível em:

https://www.oas.org/es/cidh/prensa/comunicados/2020/066.asp. Acesso em: 4 dez. 2020.

LA POBLACIÓN carcelaria de Argentina creció un 55\% en seis años. Perfil, Argentina, 27 nov. 2019. Disponível em:

https://www.perfil.com/noticias/policia/cantidad-presos-en-argentina-subio-55-porciento-en-seis-anos.phtml\#: :text=Crisis\%20carcelaria-

,La\%20poblaci\%C3\%B3n\%20carcelaria\%20de\%20Argentina\%20creci\%C3\%B3\%20 un\%2055\%25\%20en\%20seis,representan\%20el\%2069\%25\%20del\%20pa\%C3\%AD s. Acesso em: 8 dez. 2020.

ROJAS CASTAÑEDA, Daniel. El hacinamiento en las cárceles colombianas sobrepasa 54,9\% según estadísticas del Inpec. Asuntos:legales, Bogotá, 25 mar. 2020. Disponível em: https://www.asuntoslegales.com.co/actualidad/elhacinamiento-en-las-carceles-colombianas-sobrepasa-549-segun-estadisticas-delinpec-2982618. Acesso em: 4 dez. 2020.

WORLD HEALTH ORGANIZATION. Preparedness, prevention and control of COVID-19 in prisons and other places of detention: Interim guidance: 15 March 2020. Copenhagen: WHO, 2020. Disponível em:

https://apps.who.int/iris/bitstream/handle/10665/336525/WHO-EURO-2020-140541155-55954-eng.pdf?sequence=1\&isAllowed=y. Acesso em: 6 dez. 2020. 